\title{
Vibration-induced particle formation during yogurt fermentation-Effect of frequency and amplitude
}

\author{
Adrian Körzendörfer, ${ }^{* 1}$ Philipp Temme, † Eberhard Schlücker,† Jörg Hinrichs, ${ }^{*}$ and Stefan Nöbel ${ }^{*}$ \\ *Institute of Food Science and Biotechnology, University of Hohenheim, Garbenstr. 21, 70593 Stuttgart, Germany \\ †Department of Chemical and Biological Engineering, Friedrich-Alexander University Erlangen-Nürnberg, Cauerstr. 4, 91058 Erlangen, Germany
}

\begin{abstract}
Machinery such as pumps used for the commercial production of fermented milk products cause vibrations that can spread to the fermentation tanks. During fermentation, such vibrations can disturb the gelation of milk proteins by causing texture defects including lumpiness and syneresis. To study the effect of vibrations on yogurt structure systematically, an experimental setup was developed consisting of a vibration exciter to generate defined vibrational states and accelerometers for monitoring. During the fermentation of skim milk, vibrations (frequency sweep: 25 to $1,005 \mathrm{~Hz}$ ) were introduced at different $\mathrm{pH}$ (5.7 to 5.1 , step width 0.1 units) for 200 s. Physical properties of set gels (syneresis, firmness) and resultant stirred yogurts (visible particles, rheology, laser diffraction) were analyzed. Vibrational treatments at $\mathrm{pH} 5.5$ to 5.2 increased syneresis, gel firmness, and the number of large particles $(d>0.9 \mathrm{~mm})$; hence, this period was considered critical. The particle number increased from $34 \pm 5$ to $242 \pm 16$ particles per $100 \mathrm{~g}$ of yogurt due to vibrations at $\mathrm{pH}$ 5.4. In further experiments, yogurts were excited with fixed frequencies $(30,300$, and 1,000 $\mathrm{Hz}$ ). All treatments increased syneresis, firmness, and particle formation. As the strongest effect was observed by applying $30 \mathrm{~Hz}$, the amplitude was set to vibration accelerations of $a=5,10,15,20$, and $25 \mathrm{~m} / \mathrm{s}^{2}$ in the final experiments. The number of large particles was increased due to each treatment and a positive correlation with the amplitude was found. We concluded that vibrations during gelation increase the collision probability of aggregating milk proteins, resulting in a compressed set gel with syneresis. Resultant stirred yogurts exhibit large particles with a compact structure leading to a reduced water-holding capacity and product viscosity.
\end{abstract}

Received September 27, 2017.

Accepted January 8, 2018.

${ }^{1}$ Corresponding author: adrian.koerzendoerfer@uni-hohenheim.de
Key words: fermented milk product, sonication, graininess, texture

\section{INTRODUCTION}

Yogurt and related fermented dairy products are manufactured by microbial acidification of milk with lactic acid bacteria (Lee and Lucey, 2010). Texture attributes as appearance, flow behavior, and mouthfeel play a major role in consumers' acceptance (Jaworska et al., 2005). Texture defects such as low viscosities, graininess, or whey separation are undesired (Lucey, 2004). Milk is either fermented in the retail container (set-style yogurt) or more commonly in large fermentation tanks for the production of stirred yogurt. In the latter case, the gel is broken up in the tank at approximately $\mathrm{pH} 4.6$ and cooled. Before packaging, ingredients such as fruit, color, and so on can be added (Mokoonlall et al., 2016a). Stirred yogurt can be described as a microgel suspension consisting of protein particles that are suspended in acid whey. Typically, the particle size ranges from 2 to $100 \mu \mathrm{m}$ (van Marle et al., 1999; Weidendorfer and Hinrichs, 2010). Depending on the microstructure, the mouthfeel can become rough due to particles $>150 \mu \mathrm{m}$ (Cayot et al., 2008; Krzeminski et al., 2013). Apart from these microgel particles, particles of a size that are visible to the unaided eye can cause lumpiness and a gritty texture. Such defects can be corrected by mechanical postprocessing (Walstra et al., 2006); however, this will result in structure losses (Lucey and Singh, 2003; Mokoonlall et al., 2016a). Whether a product is rated smooth or lumpy is subjective. To evaluate the texture objectively, a method based on image analysis has been developed (Nöbel et al., 2016b).

There is several potential reasons for excessive particle formation, including protein composition (Isleten and Karagul-Yuceer, 2006; Nöbel et al., 2016a), heat treatment of milk (Remeuf et al., 2003; Küçükçetin, 2008), fermentation temperature, and starter cultures (Küçükçetin et al., 2009; Buldo et al., 2016). Moreover, mechanical damage to the gel during fermentation 
disturbs the gelation of the milk proteins and results in an inhomogeneous, lumpy texture showing visible particles. During fermentation, mechanical stress to the coagulating milk can be caused by vibrations that are generated by surrounding machines such as pumps and homogenizers (Körzendörfer et al., 2016). In addition, cleaning and sterilization steps generate vibrations due to high flow velocities and a phenomenon called water hammer (Swidersky, 2013; Kaliatka et al., 2014). Vibration measurements in a dairy factory showed various sources of vibrations that are transferred through pipelines to the fermentation tanks. Compared with the idle state, the mean vibration acceleration at a running rotary piston pump was increased by a factor of 7. The frequency spectrum measured at the running pump ranged from 10 to $10,000 \mathrm{~Hz}$ with the highest amplitudes between 100 and 1,000 Hz (Körzendörfer et al., 2016).

In the first experiments, a temporary ultrasound treatment $(45 \mathrm{kHz}, 5 \mathrm{~min})$ during fermentation at $\mathrm{pH}$ 5.4 to 5.1 resulted in a stirred product with numerous large particles (Nöbel et al., 2016b). In a previous study, an experimental setup was developed to run fermentation experiments under defined vibrational states. Low-frequency vibrations up to $1,000 \mathrm{~Hz}$ as primarily existing in industry also caused the formation of visible particles (Körzendörfer et al., 2016). The vibrational treatment of a fermentation tank $(20 \mathrm{~L})$ was carried out by means of a vibration exciter. However, not much is known about the effect of low-frequency vibrations on particle formation and further texture properties. We hypothesize that the effect of a specific vibration depends on its characteristics (i.e., occurring frequencies and respective amplitudes) because these parameters determine the sound energy. An increasing sound energy results in increased particle motions and should cause more disturbances during gelation (Müller and Möser, 2013). This study focuses on 3 subtopics. (1) Yogurts were short-term vibrated (200 s, 25 to $1,005 \mathrm{~Hz}$ ) at different $\mathrm{pH}$ during the fermentation to define a critical $\mathrm{pH}$ range. (2) Various frequencies were applied during the acquired critical pH. (3) A single frequency was set and different amplitudes were tested. After fermentation, set gels were examined first and then processed into stirred yogurt for further analyses.

\section{MATERIALS AND METHODS}

\section{Milk Pretreatment and Starter Culture}

Fresh bovine raw milk was provided by the agricultural experiment station (Meiereihof, University of Hohenheim, Germany) and skimmed at $55^{\circ} \mathrm{C}$ (SA 10,
Frautech S.r.l., Schio, Italy). The protein content was standardized to $3.40 \pm 0.01 \%$ (wt/wt) using reconstituted ultrafiltered skim milk permeate, which consisted of $5.2 \%$ (wt/wt) permeate powder (Bayolan PT, BMI e. G., Landshut, Germany) and demineralized water. Protein and fat contents were analyzed with an FTIR spectrometer (LactoScope FTIR Advance, Delta Instruments, Drachten, the Netherlands). Milk was heated to $95^{\circ} \mathrm{C}$ for $256 \mathrm{~s}$ to denature whey proteins $(>90 \%)$ and subsequently cooled to $6^{\circ} \mathrm{C}$ using a pilot plant $(150 \mathrm{~L} / \mathrm{h}$; Asepto GmbH, Dinkelscherben, Germany). Before every experiment, a quantity of $250 \mathrm{~g}$ of the frozen starter culture YC-471 (Chr. Hansen, Hørsholm, Denmark) was diluted with $1,000 \mathrm{~g}$ of skim milk $\left(6^{\circ} \mathrm{C}\right)$ to ensure a homogeneous distribution of the 2 species Lactobacillus bulgaricus and Streptococcus thermophilus. The stock solution (20\% wt/wt) was thawed at room temperature with occasional stirring before use.

\section{Yogurt Fermentation}

Cylindric polypropylene containers $(d=102 \mathrm{~mm}, l$ $=155 \mathrm{~mm}$ ) were filled with a quantity of $900 \mathrm{~g}$ of preheated milk $\left(45^{\circ} \mathrm{C}\right)$ and put in a water bath $(\mathrm{Ju}-$ labo ED, Julabo Labortechnik GmbH, Seelbach, Germany) at $42^{\circ} \mathrm{C}$. After temperatures had equilibrated, milks were inoculated with $2.25 \mathrm{~mL}$ of starter culture stock solution (i.e., $0.05 \%$ in total) and fermented at $42^{\circ} \mathrm{C}$ until $\mathrm{pH}$ 4.6. Acidifications were continuously monitored with $\mathrm{pH}$ sensors (SE555X/2-NMSN, Knick Elektronische Messgeräte GmbH \& Co. KG, Berlin, Germany; software: DAQ Factory Express, Azo Inc., Memphis, TN). During fermentation, yogurt samples were temporarily treated with a vibration exciter as described in the section below. To negate any effects of moving the containers to the vibration exciter, controls were also taken out of the water bath at the same time and put back like the vibrated samples. Additionally, one yogurt sample remained in the water bath during the complete acidification (reference). Fermentations were stopped at $\mathrm{pH} 4.6$ by immersing the containers in iced water for $60 \mathrm{~min}$. Samples were stored overnight at $10^{\circ} \mathrm{C}$ until further analysis. The number of independent repetitions of the experiments was $i \geq 3$.

\section{Applying Vibrations}

Vibrations are generated by an electrodynamic vibration exciter/shaker (TV 51110, Tira GmbH, Schalkau, Germany), which is powered by an amplifier (BAA 60; Tira GmbH). The frequency range of the shaker is 2 to $7,000 \mathrm{~Hz}$, and the rated force is $100 \mathrm{~N}$. The vibration 
exciter is controlled by a frequency generator (LabView, V. 13.0, National Instruments, Austin, TX), which enables generation of individual frequencies or sweeps. A stainless-steel table is mounted on the vibration exciter on which the containers with fermenting milk can be attached. A piezoelectric acceleration sensor with internal amplification (8714B, Kistler Instrumente AG, Winterthur, Switzerland) mounted on the table is used to monitor the vibrations and set acceleration amplitudes. The obtained signals were digitalized with analog input modules (NI 9237, National Instruments) and an A/D converter (NI cDAQ-9174, National Instruments). Processing and storage of data were carried out via LabView. Recorded time domain signals were converted to frequency spectra by means of Fast Fourier Transform using a FlatTop window function after a band-pass filter (3 to $10,000 \mathrm{~Hz}$, Butterworth) via DIAdem 2014 (National Instruments). The frequency domain was used to ensure that the desired frequencies appear at the table itself. Amplitudes of the vibration accelerations were set using the time domain of the raw signal.

To identify critical $\mathrm{pH}$ ranges during fermentation first, vibrations were applied at $\mathrm{pH} 5.7$ to 5.1 in steps of $\Delta \mathrm{pH}=0.1$ for $200 \mathrm{~s}$. In detail, a frequency sweep was performed from 25 to $1,005 \mathrm{~Hz}$ within $10 \mathrm{~s}$ and replayed 20 times. The power of the amplifier was kept constant during the sweep but was set to an acceleration of $50 \mathrm{~m} / \mathrm{s}^{2}$ at a monotonous frequency of $30 \mathrm{~Hz}$ before the experiments. In further experiments, individual frequencies $(30,300$, and $1,000 \mathrm{~Hz})$ were applied at $\mathrm{pH}$ 5.4 for $200 \mathrm{~s}$ to figure out which kind of vibrations mainly cause particle formation. In the last series of experiments, the frequency was set to $30 \mathrm{~Hz}$ and different acceleration amplitudes $(5,10,15,20$, and 25 $\mathrm{m} / \mathrm{s}^{2}$ ). Samples were vibrated from $\mathrm{pH} 5.6$ to 5.2 that corresponded to approximately $20 \mathrm{~min}$.

\section{Syneresis and Firmness of Set Yogurts}

Spontaneously expelled whey was removed and quantified as suggested by Lucey (2004) before the firmness measurements and poured back afterward. The quantity of the whey is expressed as

$$
\text { Syneresis }(\%)=\frac{\text { expelled whey }(\mathrm{g})}{\text { initial milk }(\mathrm{g})} \times 100 \text {. }
$$

Additionally, the protein content of the remaining set gel $\left(P_{\text {eff }}\right)$ was calculated according to Equation [2]. The protein content of expelled whey was determined to be $0.8 \%$.

$$
P_{\text {eff }}(\%)=\left(\frac{3.4}{\frac{100-\text { syneresis }(\%)}{100}}-\text { syneresis }(\%) \times 0.008\right) .
$$

Penetration tests of set yogurts were done with a universal testing machine (5944, Instron, Norwood, MA; load cell: $50 \mathrm{~N}$; software: Bluehill 3). Sample temperature was $10^{\circ} \mathrm{C}$ and 7 measuring repetitions were done per container using a cylindrical probe $(d=10 \mathrm{~mm})$. The test speed was set to $0.5 \mathrm{~mm} / \mathrm{s}$ for $30 \mathrm{~s}$ and the force at the first local maximum $\left(F_{\max }\right)$ was determined.

\section{Stirred Yogurt Production}

For the production of stirred yogurt, a method suggested by Mokoonlall et al. (2016b) was modified. After firmness and syneresis were determined, set yogurt gels (900 g) were slightly broken with a spoon and sheared at approximately $10^{\circ} \mathrm{C}$ with a large syringe $\left(d_{\mathrm{i}}=58\right.$ $\mathrm{mm}, l=290 \mathrm{~mm}$; Hausammann \& Co AG, Zürich, Switzerland) through a nozzle $\left(d_{\mathrm{i}}=3 \mathrm{~mm}, l=25 \mathrm{~mm}\right)$. The piston was moved by the universal testing machine (5944, Instron, load cell: $2 \mathrm{kN}$ ) to ensure a constant flow rate of $600 \mathrm{~mL} / \mathrm{min}$ that corresponds to a representative shear rate $\left(\dot{\gamma}_{\text {rep }}\right)$ of $3,770 \mathrm{~s}^{-1}$ (residence time $t$ $=1.8 \mathrm{~ms}$ ) within the nozzle

$$
\dot{\gamma}_{\text {rep }}=\left(\begin{array}{ll}
4 & \dot{V}
\end{array}\right) /\left(\pi r^{3}\right)
$$

where $\dot{V}$ is the volume flow $\left(\mathrm{m}^{3} / \mathrm{s}\right)$ and $r$ is the radius of the nozzle $(\mathrm{m})$. Stirred yogurts were stored in containers $(500 \mathrm{~mL})$ at $10^{\circ} \mathrm{C}$ until further analyses (transmission images, laser diffraction). For rheological measurements, separate samples in glass jars $(100 \mathrm{~mL}, 3$ jars per sample) were stored for $7 \mathrm{~d}$ at $10^{\circ} \mathrm{C}$ and not disturbed until analyses to allow rebodying.

\section{Transmission Images: Large Particles}

Large particles with $d \geq 0.9 \mathrm{~mm}$ (15 pixels) were quantified by means of image analysis according to previous studies (Nöbel et al., 2016b). Briefly, a thin layer $(1.2 \mathrm{~mm})$ of the yogurt sample was scratched out with a scraper and metal bar spacers on a glass plate from which transmission images (source of light: Comic Master Tracer LED-A4, Too Marker Products Inc., Tokyo, Japan) were taken using a digital camera (8-bit grayscale, MicroPublisher 3.3 RTV, QImaging, Surrey, Canada). One image $(120 \times 90 \mathrm{~mm})$ represents 
approximately $12 \mathrm{~g}$ of yogurt. Particles were classified and counted using Matlab 8.3 (R2014a) and Matlab's Image Processing Toolbox 8.2 (The MathWorks Inc., Natick, MA). Particle numbers are given per $100 \mathrm{~g}$ of yogurt. Data were obtained from at least 12 independent images per sample.

\section{Protein Content of Yogurt and Large Particles}

The nitrogen content of yogurt samples was determined according to the method of Dumas (International Dairy Foundation, 185:2002) using a nitrogen analyzer (Dumatherm DT, Gerhardt GmbH \& Co. KG, Königswinter, Germany). The total protein content was calculated by multiplying the nitrogen content by the conversion factor of 6.38. Furthermore, approximately 50 large particles were manually picked with a pincette from the scratched-out samples and analyzed separately.

\section{Laser Diffraction Spectroscopy}

Particle size distributions of small microgel particles $(d<0.5 \mathrm{~mm})$ were determined by means of static light scattering (LS 13320, Beckman-Coulter Inc., Miami, FL) as described by Mokoonlall et al. (2015). Yogurt samples were diluted with demineralized water $(6 \% \mathrm{wt} /$ wt) and stirred for $15 \mathrm{~min}$ at $150 \mathrm{rpm}$. Approximately $1 \mathrm{~mL}$ of the diluted sample was added to the dispersion unit (obscuration: 14-16\%). Three successive runs were performed of each sample. Measurements were repeated 3 times and the Sauter mean diameter $\left(d_{3,2}\right)$ and volume-weighted 90th percentile $\left(d_{90}\right)$ were calculated.

\section{Rheological Characterization}

Stirred yogurt samples were analyzed $7 \mathrm{~d}$ after the mechanical treatment at $10^{\circ} \mathrm{C}$ using a stress-controlled rheometer (AR2000ex, TA Instruments, New Castle, DE) with a coaxial cylinder geometry $\left(d_{\mathrm{o}}=15 \mathrm{~mm}, d_{\mathrm{i}}\right.$ $=14 \mathrm{~mm}, l=42 \mathrm{~mm}$ ). After an equilibration time of 10 min, storage moduli $\left(\mathbf{G}^{\prime}\right)$ were determined by means of oscillating measurements in the linear viscoelastic region $(\gamma=0.0025)$ by performing a 30-s time sweep at a constant frequency of $10 \mathrm{rad} / \mathrm{s}$. Flow curves were measured in successive rotational measurements using the same sample. The shear rate was linearly increased from 0 to $500 \mathrm{~s}^{-1}$ within $3 \mathrm{~min}$. After a hold step (3 min, $500 \mathrm{~s}^{-1}$ ), the shear rate was linearly decreased to 0 $\mathrm{s}^{-1}$ within $3 \mathrm{~min}$. Measurements were repeated 3 times and the maximum shear stress was calculated. Furthermore, the apparent viscosity $\eta_{100}$ was calculated at a shear rate of $100 \mathrm{~s}^{-1}$ as this parameter was associated with the perceived oral viscosity (Skriver et al., 1999).

\section{Statistical Analyses}

Statistical analyses were conducted with SigmaPlot (v. 12.5, Systat Software Inc., San Jose, CA). A Mann-Whitney U test served to evaluate the effect of vibrations between 2 groups (control versus vibrated sample). A 1-way ANOVA on ranks was performed to compare multiple groups. Results are given as arithmetic means and standard errors. A significance level of $\alpha$ $=0.05$ was chosen in all cases.

\section{RESULTS AND DISCUSSION}

\section{Identifying Critical pH Ranges}

Fermentations could be repeated within $222 \pm 4$ min at $42^{\circ} \mathrm{C}$. In the first series of experiments, vibrations (frequency sweep, 25 to 1,005 Hz) were applied for 200 $\mathrm{s}$ at different $\mathrm{pH}$ during fermentation.

Set Yogurt Analysis. Results of physical analyses are shown in Table 1. Yogurt samples that remained in the water bath during the entire fermentation (reference) exhibited $0.63 \pm 0.12 \%$ syneresis. To apply vibrations, it was necessary to move the containers from the water bath on the vibration exciter and back after the treatment. Therefore, the sole effect of moving the containers out of the water bath was also investigated (controls). Syneresis of controls moved at different $\mathrm{pH}$ ranged from $0.33 \%(\mathrm{pH} 5.7)$ to $1.62 \%(\mathrm{pH} 5.6)$ but was not increased significantly in comparison to the reference. The vibration treatment for $200 \mathrm{~s}$ at $\mathrm{pH} 5.7$ and 5.6 had no effect on syneresis. In contrast, an increase $(P<0.05)$ of syneresis by a factor of 5 occurred when yogurts were vibrated at $\mathrm{pH} 5.5$ to 5.2 (Table 1). Yogurt treated at $\mathrm{pH} 5.3$ exhibited $3.55 \pm 0.34 \%$ syneresis, and the corresponding control exhibited only $0.57 \pm 0.06 \%$. No effect was found when vibrations were applied at $\mathrm{pH}$ 5.1. Syneresis is the shrinkage of the set gel and is primarily caused by rearrangements of the network. Even if the milk is slightly disturbed (e.g., due to shaking) when the gelation has just started ( $\mathrm{pH}$ 5.5 to 5.2), the gel is still weak and may fracture locally with further occurring whey separation (Walstra et al., 2006; Tamime and Robinson, 2007).

The firmness of the set gels was measured by means of penetration tests, and calculated maximum forces are listed in Table 1. Controls exhibited means from 73.7 to $88.9 \mathrm{mN}$; however, they did not differ significantly from the sample that was kept in the water bath (reference). The firmness was increased $(P<0.05)$ due to vibrations at $\mathrm{pH} 5.6$ to 5.3 . Vibrations at $\mathrm{pH} 5.4$ increased the firmness from $73.7 \pm 3.6 \mathrm{mN}$ (control) to $85.6 \pm 3.5 \mathrm{mN}$ (vibrated). Yogurts with considerable syneresis generally exhibited a higher gel firmness. 
Table 1. Physical properties of set and corresponding stirred yogurts vibrated at different $\mathrm{pH}$ for 5 min with a frequency sweep $(25 \text { to } 1,005 \mathrm{~Hz})^{1}$

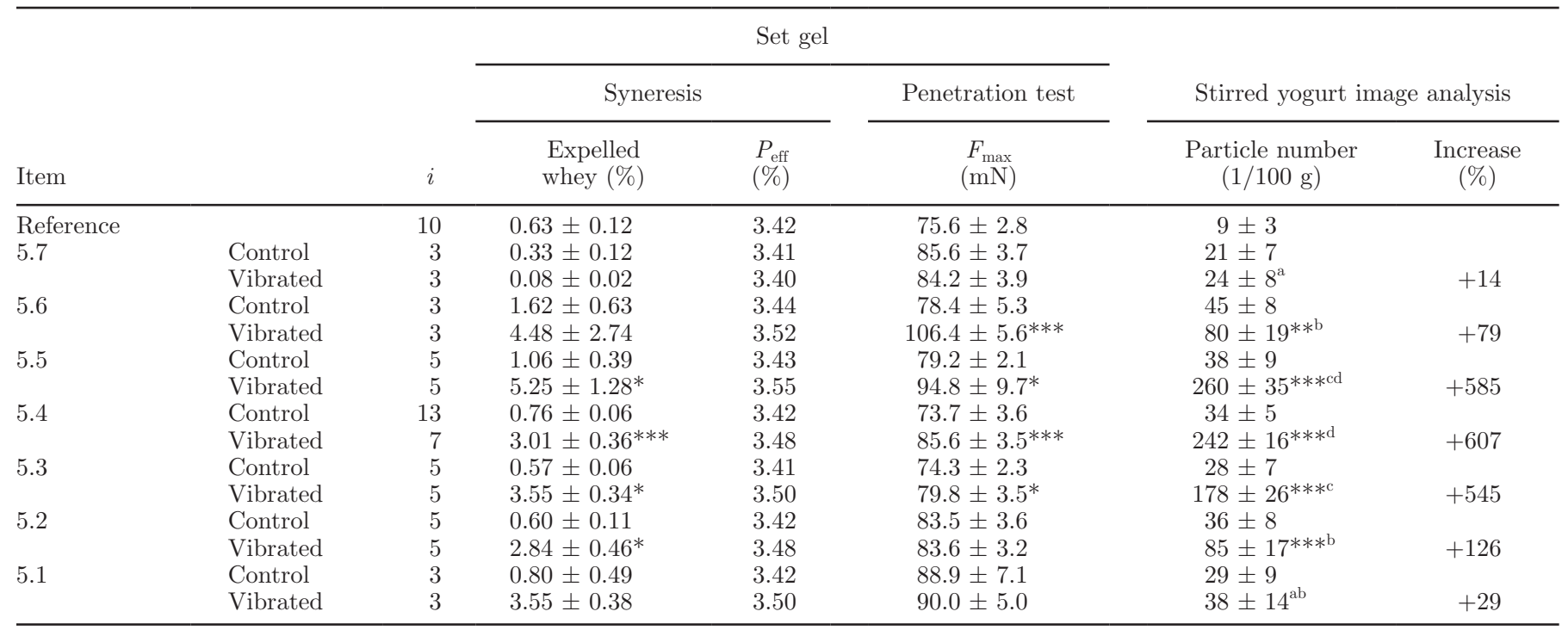

${ }^{\mathrm{a}-\mathrm{d}}$ Particle numbers of vibrated samples with different superscripts differ significantly $(P<0.05)$.

${ }^{1}$ Protein contents of the set gels without surface whey were calculated $\left(P_{\text {eff }}\right)$. Indices indicate that vibrated samples differ significantly from the respective controls. $F_{\max }=$ gel firmness. The number of independent repetitions of the experiments was $i \geq 3$. Results are given as arithmetic means and SE.

${ }^{*} P<0.05,{ }^{* *} P<0.01$, and ${ }^{* * *} P<0.001$.

Penetration tests were carried out after surface whey had been poured off. As expelled whey contained $0.8 \%$ protein, the protein content of the remaining gels was increased due to syneresis ( $P_{\text {eff }}$, Table 1). Generally, higher protein contents yield firmer gels (Tamime and Robinson, 2007) regardless of the effect of vibrations.

Stirred Yogurt Analysis. Figure 1 shows the number of large particles per $100 \mathrm{~g}$ of yogurt vibrated for $200 \mathrm{~s}$ at different $\mathrm{pH}$ during fermentation. The yogurt that was not taken out of the water bath during fermentation (reference) showed a completely smooth texture and exhibited $9 \pm 3$ particles per $100 \mathrm{~g}$. The particle numbers of controls ranged from $21 \pm 7(\mathrm{pH}$ $5.7)$ to $45 \pm 8$ (pH 5.6) particles per 100 g. Hence, moving the containers resulted in a slight increase of large particles; however, the effect was small and yogurts with less than 50 particles per $100 \mathrm{~g}$ were still smooth. Short-term vibrations at $\mathrm{pH} 5.6$ to 5.2 increased the particle number (Table 1), particularly at $\mathrm{pH} 5.5,5.4$, and $5.3(P<0.001)$. The strongest effect was observed when vibrations were applied at $\mathrm{pH}$ 5.4. In this case, the particle number rose from $34 \pm 5$ to $242 \pm 16$ particles per $100 \mathrm{~g}(+600 \%)$. Because the vibration treatment at $\mathrm{pH} 5.5$ to 5.2 increased syneresis, gel firmness, and particle number, this period was considered critical. The isoelectric point of native casein is 4.6; however, for yogurt manufacture, milk is heat treated to denature whey proteins that associate with casein micelles (Dannenberg and Kessler, 1988). Due to the

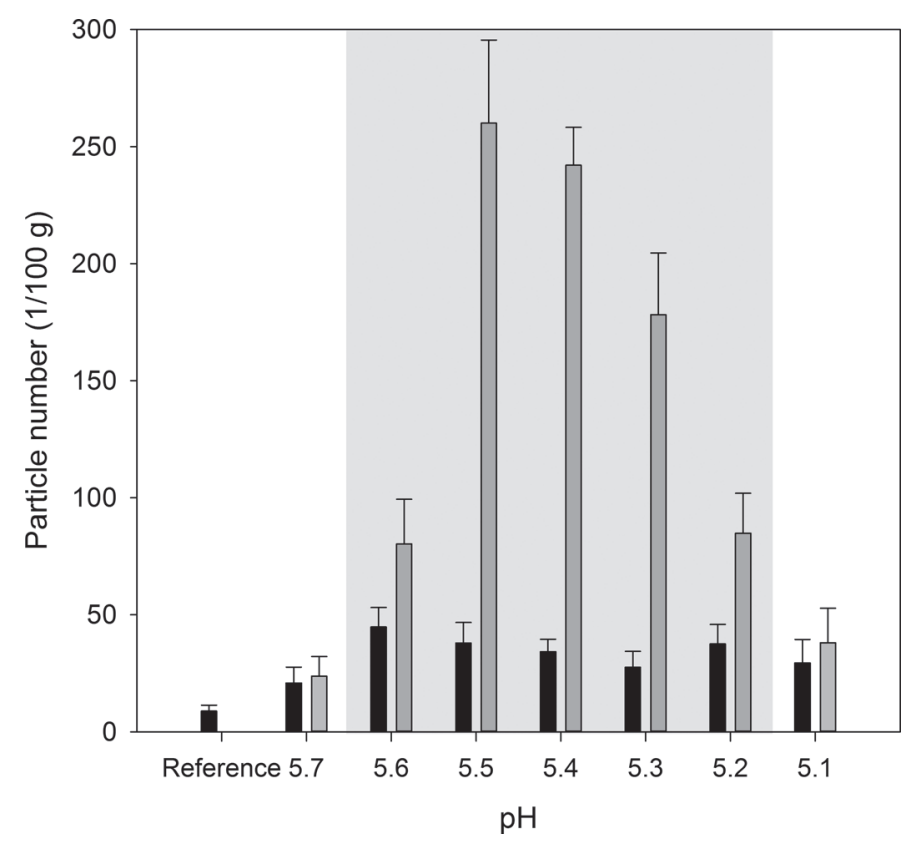

Figure 1. Number of large particles $(d>0.9 \mathrm{~mm})$ per $100 \mathrm{~g}$ of yogurt determined by image analysis. Black and gray bars represent particle numbers depending on $\mathrm{pH}$ of controls and vibrated yogurts, respectively. Vibration treatments were performed for $200 \mathrm{~s}$ with a vibration exciter and a frequency sweep (25 to 1,005 Hz). Reference gives the particle number of the yogurt that was not taken out of the water bath during fermentation. The light gray area represents the $\mathrm{pH}$ range where the particle numbers were significantly increased due to vibrations $(P<0.05)$. Error bars represent SE. 
higher IEP of $\beta-\mathrm{LG}$, the gelation point is shifted to $\mathrm{pH}$ 5.3 (Lee and Lucey, 2010).

To determine critical stages during the fermentation, similar experiments were done by Nöbel et al. (2016b). Yogurts were sonicated for $5 \mathrm{~min}$ in the $\mathrm{pH}$ range 5.7 to 5.1 in $0.1 \mathrm{pH}$ steps. Sonication was carried out in an ultrasonic water bath $(45 \mathrm{kHz}, 200 \mathrm{~W})$. Large particles $(d>0.7 \mathrm{~mm})$ were quantified as well by image analysis. Both Nöbel et al. (2016b) and the present study showed that sonication/vibrations at $>\mathrm{pH} 5.6$ had no effect on particle formation and yogurt structure in general. In this stage, casein micelles are still stabilized electrostatically and their size is not altered (Hassan et al., 1995a,b). Vibrations that lead to more collisions and local shearing will not disturb the structure of the final product as gelation has not started yet. In contrast, at $\mathrm{pH}<5.1$, a basic gel network has already been formed. The network units are larger than the native casein micelles (Heertje et al., 1985), and at this point, the viscoelastic structure is barely prone to moderate vibrations anymore.

The particle numbers in Nöbel et al. (2016b) were increased in the $\mathrm{pH}$ range 5.4 to 5.1 by a factor of approximately 4 due to sonication. As these results and the present study show, fermenting milk is mechanically sensitive to both vibration-induced syneresis and particle formation in the $\mathrm{pH}$ range 5.5 to 5.2. During this stage, most of the colloidal calcium phosphate is removed from the casein micelles without causing dissociation. Micelle-like casein particles aggregate and structures with cavities where serum is entrapped are formed (Singh et al., 1996). Nevertheless, different approaches about the micelles' behavior during acidification have been suggested (Lucey and Singh, 1998). According to our results, the structure can be disrupted just before and after the gel point $\left(\mathrm{G}^{\prime} \geq 1 \mathrm{~Pa}\right)$; hence, we differentiate 2 mechanisms: (a) Before the gelation has just started which is up to a $\mathrm{pH}$ of approximately 5.3 (Lee and Lucey, 2010), vibrations increase the collision probability of the destabilized casein micelles. The milk is still liquid and proteins are freely moving due to Brownian motion. As the zeta potential is already reduced, colliding particles are sticky and associate more frequently to larger aggregates. (b) Vibrations disturb the immature continuous gel network $\left(\mathrm{G}^{\prime}>1 \mathrm{~Pa}\right)$ that has just been formed. At this time, its structure is weak so that vibrations can cause local displacements within the network. Occurring flow forces break fine network strands that in turn results in more rearrangements of the network and syneresis. We conclude that particle formation and syneresis were most distinct in the range $\mathrm{pH} 5.5$ to 5.3 because in this state casein micelles are still motile and the network has not been consolidated. After the actual gelation has happened at approximately $\mathrm{pH} 5.25 \pm 0.5$, proteins are highly cross-linked and less sensitive to vibrations.

\section{Effect of Different Frequencies}

Vibration-induced particle formation was most distinct when the vibrations were applied at $\mathrm{pH}$ 5.4. In further experiments, the treatment was done only at this $\mathrm{pH}$. As a frequency sweep (25 to $1,005 \mathrm{~Hz}$ ) was performed for initial experiments, the next step was to investigate the effect of single frequencies that were part of the sweep, namely 30, 300, and 1,000 Hz.

Set yogurts excited with 300 and 1,000 Hz showed similar syneresis as the yogurts that were treated with the sweep (Table 2). Most whey was expelled from yogurt samples vibrated with $30 \mathrm{~Hz}(6.65 \pm 2.30 \%)$;

Table 2. Physical properties of set and corresponding stirred yogurts vibrated at $\mathrm{pH} 5.4$ for $200 \mathrm{~s}$ with different frequencies ${ }^{1}$

\begin{tabular}{|c|c|c|c|c|c|c|}
\hline \multirow[b]{3}{*}{ Item } & \multirow[b]{3}{*}{$i$} & \multicolumn{3}{|c|}{ Set gel } & & \\
\hline & & \multicolumn{2}{|c|}{ Syneresis } & \multirow{2}{*}{$\begin{array}{c}\text { Penetration test } \\
F_{\max } \\
(\mathrm{mN})\end{array}$} & \multicolumn{2}{|c|}{ Stirred yogurt image analysis } \\
\hline & & $\begin{array}{l}\text { Expelled } \\
\text { whey (\%) }\end{array}$ & $\begin{array}{l}P_{\text {eff }} \\
(\%)\end{array}$ & & $\begin{array}{c}\text { Particle number } \\
\quad(1 / 100 \mathrm{~g})\end{array}$ & $\begin{array}{c}\text { Increase } \\
(\%)\end{array}$ \\
\hline Control & 13 & $0.76 \pm 0.06$ & 3.42 & $73.7 \pm 3.6$ & $34 \pm 5$ & \\
\hline Sweep & 7 & $3.00 \pm 0.36^{* * *}$ & 3.48 & $85.6 \pm 3.5^{* * *}$ & $242 \pm 16^{* * * \mathrm{~b}}$ & +607 \\
\hline $30 \mathrm{~Hz}$ & 4 & $6.65 \pm 2.30^{* *}$ & 3.59 & $101.7 \pm 8.6^{* * *}$ & $220 \pm 44^{* * * \mathrm{~b}}$ & +544 \\
\hline $300 \mathrm{~Hz}$ & 4 & $2.89 \pm 0.94^{* *}$ & 3.48 & $84.3 \pm 7.0^{* * *}$ & $73 \pm 12^{* * * a}$ & +113 \\
\hline $1,000 \mathrm{~Hz}$ & 4 & $2.35 \pm 0.85^{* *}$ & 3.46 & $76.5 \pm 6.3^{*}$ & $104 \pm 26^{* * * a}$ & +205 \\
\hline
\end{tabular}




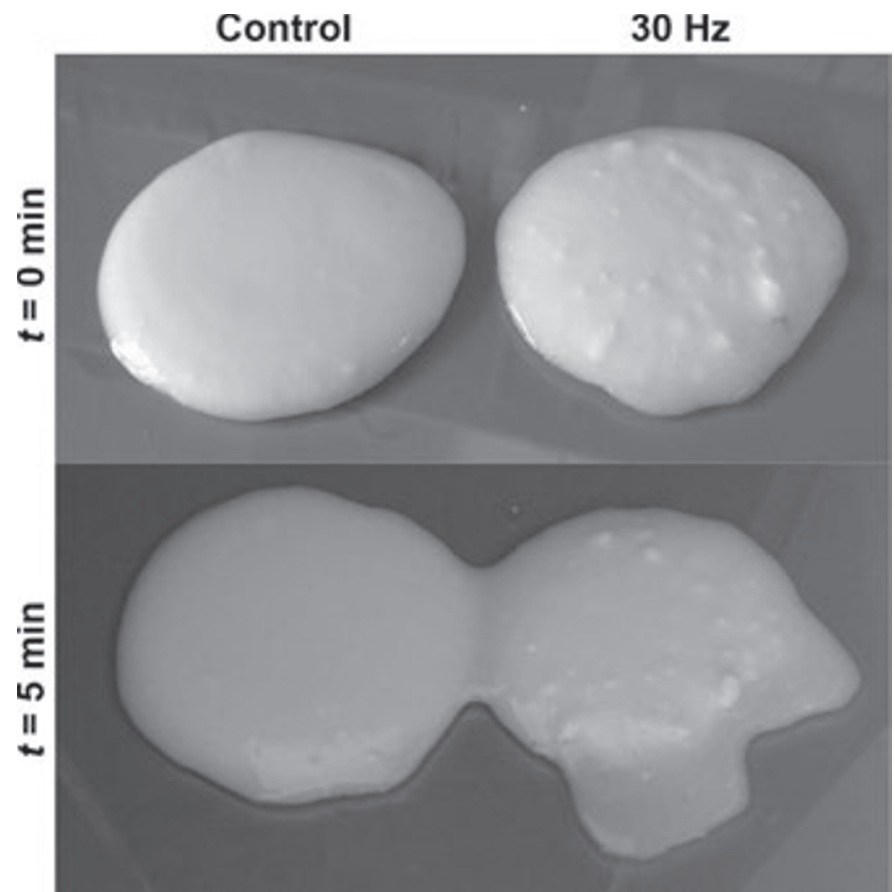

Figure 2. Manually stirred yogurt samples recently taken out of the container (above, $t=0 \mathrm{~min}$ ) and after $5 \mathrm{~min}$ (below). Left: control; right: vibrated at $30 \mathrm{~Hz}$ during fermentation at $\mathrm{pH} 5.4$ for $200 \mathrm{~s}$.

thus, the protein content of the sole set gel was remarkably increased $\left(P_{\text {eff }}=3.59 \%\right)$ compared with the other samples (Table 2). This also resulted in the highest gel firmness with a maximum force of $101.7 \pm 8.6 \mathrm{mN}$.

Figure 2 shows manually broken yogurts that underwent a comparable mechanical treatment similar to gels that have been stirred up in a large tank right after fermentation. Although only weak stirring was applied, the control showed a smooth texture. The sample vibrated at $30 \mathrm{~Hz}$ was lumpy and exhibited a decreased water-holding capacity. Even a few minutes after the yogurt was taken out of the cup, considerable wheying off occurred. After additional shearing, particle numbers of all vibrated yogurts were increased compared with the control $(P<0.001)$. Frequencies of 300 and $1,000 \mathrm{~Hz}$ increased the particle formation by 113 and $205 \%$, respectively (Table 2 ). The excitation at $30 \mathrm{~Hz}$ resulted in $220 \pm 44$ particles per $100 \mathrm{~g}(+544 \%)$; that is, the effect was equal to the excitation with the entire frequency sweep $(242 \pm 16$ particles per $100 \mathrm{~g}$; Table 1).

Mechanisms in the Fluid. The results illustrate that all tested frequencies affected the physical properties of the yogurt, in particular the formation of large particles. When comparing the effect of the different single frequencies to the sweep, it becomes clear that yogurt texture was mainly affected by lower frequencies. When applying $30 \mathrm{~Hz}$, waves on the surface of the liquid were even visible to the naked eye. This was due to the fact that the mechanical displacements of the vibration exciter (= maximum distance that the vibrating table moves up and down) are frequency dependent. Sound energy in a fluid is the sum of the kinetic and potential energy in the sound field where the potential energy compresses the fluid and the kinetic energy is converted to the movement of molecules. Accordingly, the sound energy depends on the amplitude of the vibration and its frequency. At constant sound pressure and amplitude, the energy is proportional to the frequency (Fahy and Gardonio, 2007; Müller and Möser, 2013). In this study, the power of the amplifier driving the shaker was kept constant when generating different frequencies. Thus, the displacement of the shaker increased the lower the frequency was set. As a result, the table mounted on the shaker also experienced that change in displacement according to the frequency. Higher displacements at the table resulted in higher amplitudes in the fermented milk. Hence, higher motion within the yogurt was caused by the vibrations, and as a consequence, gels vibrated at $30 \mathrm{~Hz}$ were mechanically disturbed with a higher kinetic energy leading to a higher collision probability of aggregating proteins. In this way, larger aggregates with a compact structure were formed. Additionally, recently formed noncovalent bonds between network units tend to be broken more frequently, resulting in more rearrangements and further syneresis.

Differentiation of Low Frequencies to Ultrasound. All yogurt samples treated with the vibration exciter show similar common properties, no matter which frequency was applied. Basically, treated yogurts exhibited considerable syneresis, a higher gel firmness due to the increased $P_{\text {eff }}$, and an increased particle number. In Körzendörfer et al. (2017), we performed fermentation experiments under almost identical conditions (i.e., milk composition, starter culture, fermentation temperature, and shear treatment). However, the sonication was done with an ultrasound water bath (35 $\mathrm{kHz}$ ) at $\mathrm{pH} 5.2$ for $5 \mathrm{~min}$. Control yogurts only exhibited little syneresis $(<1 \%)$ whereas the sonicated set gels exhibited remarkable whey separation $(>9 \%)$. The ultrasound treatment increased the particle number by $150 \%$. The firmness $\left(F_{\max }\right)$ of the set gels however was reduced by $28 \%$ due to ultrasound, which is contrary to the effect of low-frequency vibrations applied in the present study. As a result, ultrasound as well as lower frequencies up to $1,000 \mathrm{~Hz}$ affect gelation during fermentation by inducing large and compact protein clusters that are still present as visible particles in the stirred product.

However, ultrasound treatments during fermentation affected the gel more severely by even weakening the 
network structure and firmness. The effects of ultrasound as well as its applications on dairy products and other foods have been widely reviewed (Ashokkumar et al., 2010; Ashokkumar, 2015). As the passage of ultrasound in a liquid matrix generates mechanical agitation and other physical effects due to acoustic cavitation, it is conceivable that milk gels are severely damaged by an ultrasonic treatment. Generally, there is low frequency/high intensity and high frequency/low intensity ultrasound. The latter ranges from $200 \mathrm{kHz}$ to $1 \mathrm{MHz}$ and has barely been used in food processing, apart from application in some quality controls (Chandrapala et al., 2012b). Low-frequency ultrasound (20 to $40 \mathrm{kHz}$ ), as applied in the study of Körzendörfer et al. (2017), generates strong shear (Mason and Peters, 2002). Such effects are beneficial for multiple applications, namely emulsification (Kentish et al., 2008), extractions (Paniwnyk et al., 2001; Paniwnyk et al., 2009), and cleaning (Cai et al., 2010). These examples indicate that ultrasound can induce the breaking of strands and local fractures of the weak milk gel during yogurt fermentation, resulting in a reduced gel firmness. However, it was also reported that sonication at $20 \mathrm{kHz}$ did not influence the integrity of casein micelles (Chandrapala et al., 2012a) or the structural characteristics of whey proteins (Chandrapala et al., 2011). The authors argued that this is because small proteins are less sensitive to flow forces generated by microstreaming and cavitation in comparison to large protein complexes (Chandrapala et al., 2012b).

\section{Effect of Different Amplitudes}

The last step of this study was to investigate the effect of the intensity of vibrations. As yogurts treated with $30 \mathrm{~Hz}$ showed the most syneresis and particle formation, we subsequently focused on a fixed frequency of $30 \mathrm{~Hz}$ but different amplitudes. For this purpose, samples were vibrated from pH 5.6 to 5.2 (approximately $20 \mathrm{~min}$ ) to include the period where most particles were induced [i.e., $\mathrm{pH} 5.5,5.4$, and 5.3 (Table 1)]. Amplitudes were set to a vibration acceleration of $a=$ $5,10,15,20$, and $25 \mathrm{~m} / \mathrm{s}^{2}$. Sound energy in the fluid is proportional to the amplitude when considering a fixed frequency, meaning that higher amplitudes result in higher displacements and energy levels in the samples.

Syneresis and Firmness. Physical properties of differently treated set gels and resultant stirred yogurts are listed in Table 3. Controls exhibited only $0.35 \pm$ $0.08 \%$ whey separation. Vibrations increased $(P<$ $0.01)$ expelled whey to $2.51 \pm 0.05 \%\left(a=20 \mathrm{~m} / \mathrm{s}^{2}\right)$ and $3.63 \pm 0.02 \%\left(a=25 \mathrm{~m} / \mathrm{s}^{2}\right)$. The calculated protein content $\left(P_{\text {eff }}\right)$ of the control was barely altered and the maximum force determined by penetration tests was

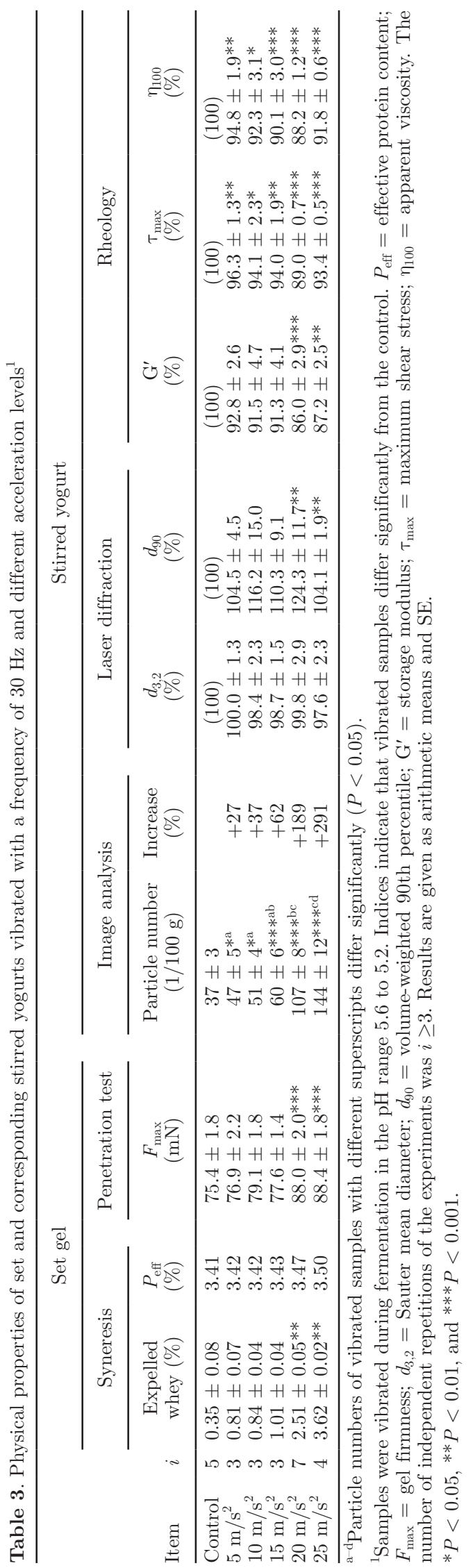

Journal of Dairy Science Vol. 101 No. 5, 2018 
$75.4 \pm 1.8 \mathrm{mN}$ (Table 3). Due to syneresis, treated samples reached calculated protein contents up to $3.5 \%$. Gel firmness of vibrated samples excited at 5, 10, and $15 \mathrm{~m} / \mathrm{s}^{2}$ was increased by trend, however, a significant increase $(P<0.001)$ only occurred when the vibration acceleration was $\geq 20 \mathrm{~m} / \mathrm{s}^{2}$. The maximum force rose by $17 \%$ to $88.4 \mathrm{mN}\left(a=25 \mathrm{~m} / \mathrm{s}^{2}\right)$. Both syneresis and gel firmness of set gels were not affected below $20 \mathrm{~m} / \mathrm{s}^{2}$.

Large Particles. Textures of the stirred yogurts vibrated at $a=5$ and $10 \mathrm{~m} / \mathrm{s}^{2}$ are as smooth as the control (Figure 3). An acceleration of $15 \mathrm{~m} / \mathrm{s}^{2}$ occasionally led to large particles depending on the individual transmission image. Treatments with an acceleration of $20 \mathrm{~m} / \mathrm{s}^{2}$ remarkably altered the macroscopic structure of the stirred yogurts as transmission images show several large particles up to $4 \mathrm{~mm}$ in diameter. A higher intensity of vibrations $\left(a=25 \mathrm{~m} / \mathrm{s}^{2}\right)$ resulted in even more particles. Furthermore, according to visual assessments, the background of the images of both samples is less homogeneous due to numerous smaller macroscopic particles up to approximately $0.5 \mathrm{~mm}$. Particle numbers $(d>0.9 \mathrm{~mm})$ from image analysis are plotted in Figure 4(a). A positive correlation between the vibration acceleration and the number of large particles was found. Controls contained only $37 \pm 3$ particles per $100 \mathrm{~g}$ that was similar to the sweep experiments before (Table 2).
Particle numbers of yogurts treated with accelerations of $a=5,10$, and $15 \mathrm{~m} / \mathrm{s}^{2}$ were slightly increased $(P<$ $0.05)$. Vibration treatments with 20 and $25 \mathrm{~m} / \mathrm{s}^{2}$ led to $107 \pm 8$ and $144 \pm 12$ particles per $100 \mathrm{~g}$ that corresponds to an increase $(P<0.001)$ of 190 and $290 \%$, respectively. The particle number escalates when a vibration acceleration of $15 \mathrm{~m} / \mathrm{s}^{2}$ is exceeded. The strong correlation $\left(\mathrm{R}^{2}>0.99\right)$ between the spontaneously expelled whey of the set gel and the particle number of the corresponding stirred yogurt is shown in Figure 4(b). We concluded that stirred yogurts with initial set gels that exhibit slight syneresis up to $1 \%$ only show a moderate number of large particles. Yogurts vibrated at 20 and $25 \mathrm{~m} / \mathrm{s}^{2}$ with syneresis $>2.5 \%$ resulted in stirred products with remarkable particle formation and a grainy structure.

Laser Diffraction and Rheology. Apart from large, visible particles, the size distribution of microgel particles was determined by laser diffraction measurements. Results are listed in Table 3 and expressed in relation to the control as a percentage to compensate variations from week to week. The Sauter mean diameter $d_{3,2}$ of the control exhibited $28.1 \pm 1.2 \mu \mathrm{m}$. No effects on the $d_{3,2}$ could be found by any vibration treatment. The 90 th percentile $d_{90}$ of the control was $66.2 \pm 4.9 \mu \mathrm{m}$ and was only increased $(P>0.01)$ by
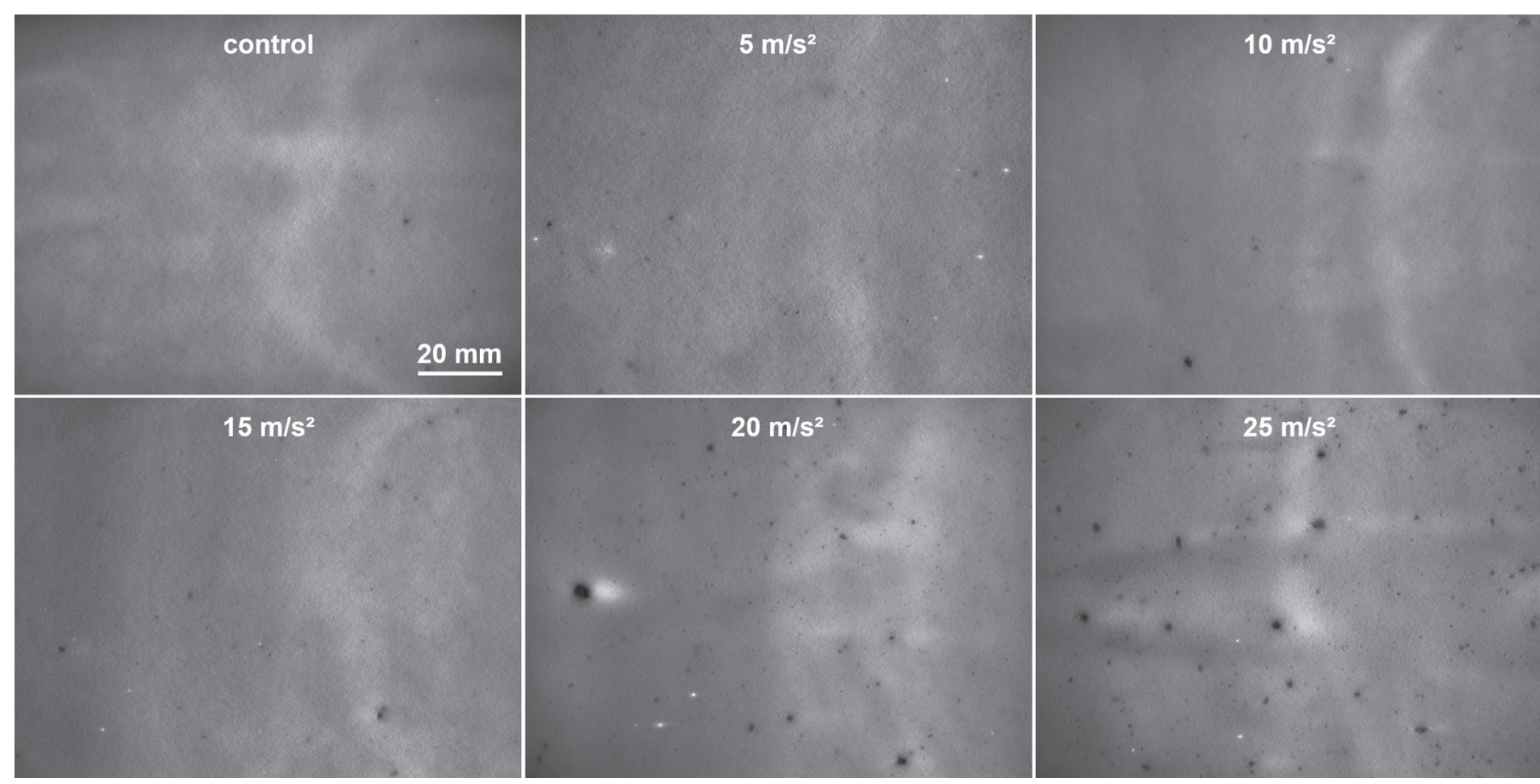

Figure 3. Transmission images $(120 \mathrm{~mm} \times 90 \mathrm{~mm}$, layer thickness $1.2 \mathrm{~mm})$ of stirred yogurts after shearing through a nozzle $(d=3 \mathrm{~mm}, l$ $=25 \mathrm{~mm}$ ). Samples were vibrated during fermentation at $\mathrm{pH} 5.6$ to 5.2 with $30 \mathrm{~Hz}$ and different vibration accelerations. Black spots represent visible particles. 
the intense treatments at 20 and $25 \mathrm{~m} / \mathrm{s}^{2}$. However, as standard errors indicate, this parameter could also be influenced by single macroscopic particles in the millimeter range. In a previous study (Körzendörfer et al., 2016), low-frequency vibrations (25 to $1,005 \mathrm{~Hz}$ ) had no effect on the size of micrometer-scale particles. We conclude that vibrations mainly affected the formation of large and visible particles.

Rheological measurements were also expressed in relation to the control (Table 3). Storage modulus of the control exhibited $\mathrm{G}^{\prime}=118.9 \pm 3.8 \mathrm{~Pa}$. Vibration treatments decreased storage moduli, but an effect $(P<0.01)$ only occurred when the acceleration was set to 20 or $25 \mathrm{~m} / \mathrm{s}^{2}$. The apparent viscosity and the maximum shear stress of the control were $\eta_{100}=331$ $\pm 6 \mathrm{mPas}$ and $\tau_{\max } 35.9 \pm 0.5 \mathrm{~Pa}$, respectively. Both parameters were decreased $(P<0.05)$ due to vibration treatments in all cases. The $\eta_{100}$ and $\tau_{\max }$ of the yogurt vibrated at $20 \mathrm{~m} / \mathrm{s}^{2}$ showed the highest decrease and were diminished by 11.8 and $11.0 \%(P<0.001, i=5)$, respectively. Yogurts treated at $25 \mathrm{~m} / \mathrm{s}^{2}$ showed slightly lower decreases $(P<0.001, i=3)$ that were likely due to the lower number of repetitions of this experiment.

Protein Content of Large Particles. To investigate the structure of large particles, additional protein analyses were done. The protein content of virtually particle-free yogurt (control) was $3.40 \pm 0.06 \%$. In contrast, single large particles that were isolated by manual picking exhibited a protein content of $9.0 \pm$ $1.5 \%$. Furthermore, the remaining outer phase of the yogurt with the highest particle number $(a=25 \mathrm{~m} /$ $\mathrm{s}^{2}$ ) had a protein content of $3.3 \pm 0.1 \%$. Our results show that large particles have a more compact and firm structure with an increased protein content. In turn, the remaining outer phase lacks the protein located in these particles. Generally, the protein content of stirred yogurt positively correlates with storage modulus $\mathrm{G}^{\prime}$ and $\tau_{\max }$ (Nöbel et al., 2016a). This is due to the higher amount of network building units and hence higher number of microgel particles. As a result, the presence of large particles lowers the protein content available to form the preferred micrometer-scale particles and causes a decreased viscosity of the whole yogurt. Nevertheless, the average protein content of the yogurts remain the same. Additionally, products containing visible particles demand a mechanical treatment before packaging associated with an additional structural breakdown (Weidendorfer et al., 2008) and a lower perceived creaminess (Sonne et al., 2014). As consumers demand products with a smooth and thick consistency (Sodini et al., 2004; Frøst and Janhøj, 2007), structure losses have to be compensated by the addition of hydrocolloids or a higher DM content (Karam et al., 2013) that in turn require duty of declaration and increased costs. The EPS-producing starter cultures are another option but often result in an altered taste and aroma (Güler-Akin et al., 2009).
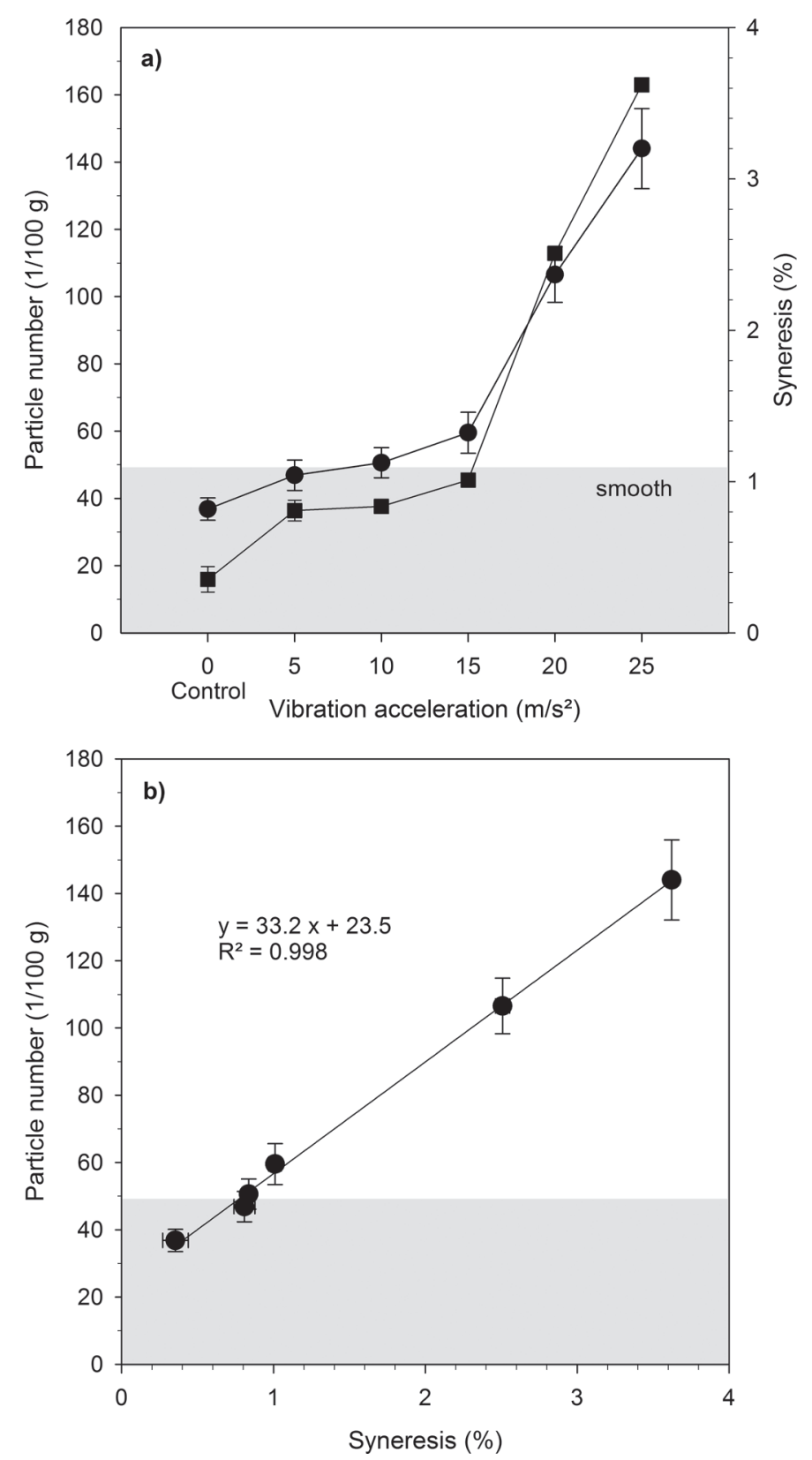

Figure 4. Syneresis of the initial set gels after fermentation and number of large particles $(d>0.9 \mathrm{~mm})$ per $100 \mathrm{~g}$ of yogurt $(\mathbf{)})$ as a function of vibration acceleration (a); number of large particles as a function of percentage syneresis (b). The vibration treatment was done during fermentation at pH 5.6 to 5.2 and a frequency of $30 \mathrm{~Hz}$. Yogurts with $<50$ particles per $100 \mathrm{~g}$ can be considered smooth (gray area). Error bars represent SE. 


\section{CONCLUSIONS}

Our experimental setup enabled the vibration excitation of small volumes $(\leq 1 \mathrm{~L})$ of milk during fermentation. Individual vibrations can be evaluated by setting defined frequencies and amplitudes. Because vibration treatments in the $\mathrm{pH}$ range 5.5 to 5.1 influenced the gelation by increasing syneresis and the number of large particles, this period is considered critical. As a precaution, disturbances due to vibrations should be avoided in practice during this period. Lower frequencies affected the gel structure most; hence, machinery used for yogurt manufacture such as pumps or agitators should be characterized regarding their acoustic behavior. Vibrations affected the gelation and particle formation primarily at vibration accelerations $>15 \mathrm{~m} /$ $\mathrm{s}^{2}$. Probably a certain vibration reduction by means of damping is already sufficient to avoid severe texture defects. To reduce the propagation of vibrations from the source to the fermentation tank, our next work will focus on the development of damping methods. Further research on the fluid-structure interaction and the propagation of oscillations in the liquid medium is necessary. Afterward, the tank volume that is affected by vibrations could be estimated. Finally, this study showed that visible particles induced by vibrations exhibited a more compact structure with an increased protein content. The protein located in these particles was lacking in the remaining stirred product, resulting in a lower bulk viscosity and water-holding capacity.

\section{ACKNOWLEDGMENTS}

This research project was supported by the Federal Ministry for Economic Affairs and Energy (via AiF) and the FEI (Forschungskreis der Ernährungsindustrie e.V., Bonn, Germany). Project AiF 19357 N.

\section{REFERENCES}

Ashokkumar, M. 2015. Applications of ultrasound in food and bioprocessing. Ultrason. Sonochem. 25:17-23.

Ashokkumar, M., R. Bhaskaracharya, S. Kentish, J. Lee, M. Palmer, and B. Zisu. 2010. The ultrasonic processing of dairy products, an overview. Dairy Sci. Technol. 90:147-168.

Buldo, P., C. Benfeldt, D. M. Folkenberg, H. B. Jensen, J. M. Amigo, S. Sieuwerts, K. Thygesen, F. van den Berg, and R. Ipsen. 2016. The role of exopolysaccharide-producing cultures and whey protein ingredients in yoghurt. Lebensm. Wiss. Technol. 72:189-198.

Cai, M., S. Zhao, and H. Liang. 2010. Mechanisms for the enhancement of ultrafiltration and membrane cleaning by different ultrasonic frequencies. Desalination 263:133-138.

Cayot, P., F. Schenker, G. Houze, C. Sulmont-Rosse, and B. Colas. 2008. Creaminess in relation to consistency and particle size in stirred fat-free yogurt. Int. Dairy J. 18:303-311.

Chandrapala, J., G. Martin, B. Zisu, S. Kentish, and M. Ashokkumar. 2012a. The effect of ultrasound on casein micelle integrity. J. Dairy Sci. 95:6882-6890.
Chandrapala, J., C. Oliver, S. Kentish, and M. Ashokkumar. 2012b. Ultrasonics in food processing. Ultrason. Sonochem. 19:975-983.

Chandrapala, J., B. Zisu, M. Palmer, S. Kentish, and M. Ashokkumar. 2011. Effect of ultrasound on the thermal and structural characteristics of proteins in reconstituted whey protein concentrates. Ultrason. Sonochem. 18:951-957.

Dannenberg, F., and H.-G. Kessler. 1988. Reaction kinetics of the denaturation of whey proteins in milk. J. Food Sci. 53:258-263.

Fahy, F., and P. Gardonio. 2007. Sound and Structural Vibration: Radiation, Transmission and Response. 2nd ed. Academic Press, Oxford, UK.

Frøst, M. B., and T. Janhøj. 2007. Understanding creaminess. Int. Dairy J. 17:1298-1311.

Güler-Akin, M. B., M. Serdar Akin, and A. Korkmaz. 2009. Influence of different exopolysaccharide-producing strains on the physicochemical, sensory and syneresis characteristics of reduced-fat stirred yoghurt. Int. J. Dairy Technol. 62:422-430.

Hassan, A. N., J. F. Frank, M. A. Farmer, K. A. Schmidt, and S. I. Shalabi. 1995a. Formation of yogurt microstructure and threedimensional visualization as determined by confocal scanning laser microscopy. J. Dairy Sci. 78:2629-2636.

Hassan, A. N., J. F. Frank, M. A. Farmer, K. A. Schmidt, and S. I. Shalabi. 1995b. Observation of encapsulated lactic acid bacteria using confocal scanning laser microscopy. J. Dairy Sci. 78:26242628.

Heertje, I., J. Visser, and P. Smits. 1985. Structure formation in acid milk gels. Food Microstructure 4:267-277.

Isleten, M., and Y. Karagul-Yuceer. 2006. Effects of dried dairy ingredients on physical and sensory properties of nonfat yogurt. J. Dairy Sci. 89:2865-2872.

Jaworska, D., B. Waszkiewicz-Robak, W. Kolanowski, and F. Swiderski. 2005. Relative importance of texture properties in the sensory quality and acceptance of natural yoghurts. Int. J. Dairy Technol. 58:39-46.

Kaliatka, A., M. Vaišnoras, and M. Valincius. 2014. Modelling of valve induced water hammer phenomena in a district heating system. Comput. Fluids 94:30-36.

Karam, M. C., C. Gaiani, C. Hosri, J. Burgain, and J. Scher. 2013. Effect of dairy powders fortification on yogurt textural and sensorial properties: A review. J. Dairy Res. 80:400-409.

Kentish, S. E., T. Wooster, M. Ashokkumar, S. Balachandran, R. Mawson, and L. Simons. 2008. The use of ultrasonics for nanoemulsion preparation. Innov. Food Sci. Emerg. Technol. 9:170-175.

Körzendörfer, A., S. Nöbel, and J. Hinrichs. 2017. Particle formation induced by sonication during yogurt fermentation-Impact of exopolysaccharide-producing starter cultures on physical properties. Food Res. Int. 97:170-177.

Körzendörfer, A., P. Temme, S. Nöbel, E. Schlücker, and J. Hinrichs. 2016. Vibration-induced particle formation during yogurt fermentation - Industrial vibration measurements and development of an experimental setup. Food Res. Int. 85:44-50.

Krzeminski, A., M. Tomaschunas, E. Köhn, M. Busch-Stockfisch, J. Weiss, and J. Hinrichs. 2013. Relating creamy perception of whey protein enriched yogurt systems to instrumental data by means of multivariate data analysis. J. Food Sci. 78:S314-S319.

Küçükçetin, A. 2008. Effect of heat treatment and casein to whey protein ratio of skim milk on graininess and roughness of stirred yoghurt. Food Res. Int. 41:165-171.

Küçükçetin, A., K. Weidendorfer, and J. Hinrichs. 2009. Graininess and roughness of stirred yoghurt as influenced by processing. Int. Dairy J. 19:50-55.

Lee, W. J., and J. A. Lucey. 2010. Formation and physical properties of yogurt. Asian-australas. J. Anim. Sci. 23:1127-1136.

Lucey, J. A. 2004. Cultured dairy products: An overview of their gelation and texture properties. Int. J. Dairy Technol. 57:77-84.

Lucey, J. A., and H. Singh. 1998. Formation and physical properties of acid milk gels: A review. Food Res. Int. 30:529-542.

Lucey, J. A., and H. Singh. 2003. Acid coagulation of milk. Pages 1001-1026 in Advanced Dairy Chemistry Volume 1: Proteins. 3rd ed. P. F. Fox and P. McSweeney, ed. Springer, New York, NY. 
Mason, T. J., and D. Peters. 2002. Practical Sonochemistry: Power Ultrasound Uses and Applications. 2nd ed. Woodhead Publishing Limited, Cambridge, UK.

Mokoonlall, A., M. Hippich, M. Struch, R. G. Berger, J. Weiss, and J. Hinrichs. 2015. Antioxidant activity of milk suppresses laccase induced radicals and the subsequent modification of acidified milk protein gels. Int. Dairy J. 60:24-31.

Mokoonlall, A., S. Nöbel, and J. Hinrichs. 2016a. Post-processing of fermented milk to stirred products: Reviewing the effects on gel structure. Trends Food Sci. Technol. 54:26-36.

Mokoonlall, A., J. Pfannstiel, M. Struch, R. G. Berger, and J. Hinrichs. 2016b. Structure modification of stirred fermented milk gel due to laccase-catalysed protein crosslinking in a post-processing step. Innov. Food Sci. Emerg. Technol. 33:563-570.

Müller, G., and M. Möser. 2013. Handbook of Engineering Acoustics. Springer, Berlin, Germany.

Nöbel, S., K. Protte, A. Körzendörfer, B. Hitzmann, and J. Hinrichs. 2016a. Sonication induced particle formation in yogurt: Influence of the dry matter content on the physical properties. J. Food Eng. 191:77-87.

Nöbel, S., N. Ross, K. Protte, A. Körzendörfer, B. Hitzmann, and J. Hinrichs. 2016b. Microgel particle formation in yogurt as influenced by sonication during fermentation. J. Food Eng. 180:29-38.

Paniwnyk, L., E. Beaufoy, J. P. Lorimer, and T. J. Mason. 2001. The extraction of rutin from flower buds of Sophora japonica. Ultrason. Sonochem. 8:299-301

Paniwnyk, L., H. Cai, S. Albu, T. J. Mason, and R. Cole. 2009. The enhancement and scale up of the extraction of anti-oxidants from Rosmarinus officinalis using ultrasound. Ultrason. Sonochem. $16: 287-292$

Remeuf, F., S. Mohammed, I. Sodini, and J. P. Tissier. 2003. Preliminary observations on the effects of milk fortification and heating on microstructure and physical properties of stirred yogurt. Int Dairy J. 13:773-782.

Singh, H., M. S. Roberts, P. A. Munro, and C. T. Teo. 1996. Acid-induced dissociation of casein micelles in milk: Effects of heat treatment. J. Dairy Sci. 79:1340-1346.

Skriver, A., J. Holstborg, and K. B. Qvist. 1999. Relation between sensory texture analysis and rheological properties of stirred yogurt. J. Dairy Res. 66:609-618.

Sodini, I., F. Remeuf, S. Haddad, and G. Corrieu. 2004. The relative effect of milk base, starter, and process on yogurt texture: A review. Crit. Rev. Food Sci. Nutr. 44:113-137.

Sonne, A., M. Busch-Stockfisch, J. Weiss, and J. Hinrichs. 2014. Improved mapping of in-mouth creaminess of semi-solid dairy products by combining rheology, particle size, and tribology data. Lebensm. Wiss. Technol. 59:342-347.

Swidersky, H. 2013. Condensation induced water hammer (CIWH)Relevance in the nuclear industry and state of science and technology. Kerntechnik 78:16-21.

Tamime, A. Y., and R. K. Robinson. 2007. Yoghurt Science and Technology. 3rd ed. Woodhead Publishing Limited, Cambridge, UK.

Van Marle, M. E., D. van den Ende, C. G. de Kruif, and J. Mellema. 1999. Steady-shear viscosity of stirred yogurts with varying ropiness. J. Rheol. (N.Y.N.Y.) 43:1643-1662.

Walstra, P., J. Wouters, and T. Geurts. 2006. Dairy Science and Technology. 2nd ed. CRC Press, Boca Raton, FL.

Weidendorfer, K., A. Bienias, and J. Hinrichs. 2008. Investigation of the effects of mechanical post-processing with a colloid mill on the texture properties of stirred yogurt. Int. J. Dairy Technol. 61:379-384.

Weidendorfer, K., and J. Hinrichs. 2010. Online particle size measurement in microgel particle suspensions: Principles and data analysis. Chemieingenieurtechnik (Weinh.) 82:1685-1691. 